\title{
Neuropsychology in the Past, Now and in the Future
}

\author{
Janna M. Glozman \\ Lomonosov Moscow State University, Psychology Department, \\ Russia, Moscow
}

\section{Нейропсихология вчера, сегодня, завтра}

\author{
Жанна М. Глозман \\ Московский государственный университет имени М. В. Ломоносова, факультет психологии, \\ Россия, Москва
}

Corresponding author. E-mail: Glozman@mail.ru

The actual intensive and extensive growth of international neuropsychology (both theoretical and applied) testified in the paper, is due to the abilities of contemporary professional neuropsychologists to meet different purposes beyond understanding of brain-behavior relationships. It makes contemporary neuropsychology an important part of the psychology of health, instead to be an aspect of the biology of health.

The value and the history of Lurian syndrome analysis are presented. The Lurian syndrome analysis (a qualitative (structural) analysis of the symptom under study), not only permits an understanding of why the subject was poor at or unable to perform a given task. Such an approach also allows us to see what other tasks, with similar cognitive demands (structure), could present difficulties for this individual (child or adult) as well as to predict the types of tasks accessible for the patient and the types of cueing efficient for him/ her. The last is possible in conditions of dialogue interaction with the patient in the process of neuropsychological assessment. Lurian approach is oriented on the process of test fulfilment (the means by which the performer achieves or better the result as well as the level of necessary help or stimulation), more than on the test result - the level of performance on a task (accuracy, time, number of mistakes and so on) with reference to some expected (normative) level of performance.

The evolution of neuropsychology coincides with the universal tendency to replace a static neuropsychology, relating the individual's behavior to fixed cerebral lesions, by a dynamic neuropsychology, which analyzes the dynamics of brain-behavior interaction in different social conditions and at different steps of ontogenic evolution. The author gives own model of neuropsychology evolution, including three overlapping and coexisting phases different in the main emphasis for neuropsychologists. In the first phase, the accent was on the brain and its relationship to different behaviors. In the second phase of neuropsychology evolution the structure 
of mental activity and neuropsychological interpretation of human cognition have been the focus of attention and afterwards their localization in the brain. The third and actually dominant phase of evolution in neuropsychology focuses on the interrelationship between a patient and his or her environment and integrates neuropsychological and real life data. This phase gave birth to social - historical or cultural - historical neuropsychology. One of the important consequences of cultural - historical approach in neuropsychology was the introduction of cultural adjustments in neuropsychological diagnostic tests, both verbal and nonverbal.

Qualitative and quantitative integration of Lurian procedures are discussed. Underlined are differences in concepts neuropsychology and neurosciences, as well as the role of cultural-historical approach in contemporary neuropsychological assessment, rehabilitation and remediation.

Three main trends can be seen in the evolution of neuropsychology after Luria: 1. Extensive further expansion of research and practice, that is, embracing numerous new domains and nosological patient groups; 2 . Combination of qualitative and quantitative approaches; 3. Social and personality-based orientation.

Luria's creative and comprehensive approach stimulates the further evolution of neuropsychology in Russia and throughout the world.

Keywords: neuropsychology; its purposes; phases of evolution; syndrome analysis; A. R. Luria; cultural neuropsychology.

Интенсивный и экстенсивный рост нейропсихологических методов исследований (как теоретических, так и прикладных) во всем мире в последние десятилетия объясняется тем, что современный нейропсихолог может решать задачи, далеко выходящие за рамки изучения связи мозга и психики. Современная нейропсихология из аспекта биологии здоровья стала важнейшим компонентом психологии здоровья.

В статье показаны история создания луриевского синдромного анализа и его значение для нейропсихологии. Луриевский подход (качественный, структурный анализ наблюдаемого симптома) позволяет не только понять, почему пациент не справляется с выполнением предложенного нейропсихологического теста или затрудняется его выполнить, но и предсказать, какие задачи со сходной психологической структурой будут трудны для данного пациента (как взрослого, так и ребенка), а какие будут ему доступны, и какие виды помощи нейропсихолога эффективны в условиях диалогового взаимодействия при нейропсихологической диагностике. Луриевский подход предполагает ориентацию в большей степени на процесс выполнения теста и анализ видов помощи экспериментатора, позволяющих достичь или улучшить результат, чем на сам результат (точность, время, число ошибок) с учетом нормативных данных.

Развитие нейропсихологии связано с общей тенденцией к замене статической нейропсихологии, жестко связывающей поведение индивидуума с определенными областями мозга, динамической нейропсихологией, изучающей взаимодействие мозга и психики на разных этапах онтогенеза и в различных социальных условиях. Проанализирована динамика развития нейропсихологии, дана авторская модель ее развития как континуума из трех взаимосвязанных этапов. На первом этапе в центре внимания 
нейропсихологов было взаимодействие мозга и различных форм поведения, на втором - структура психических процессов и нейропсихологическая характеристика познания. На третьем, в настоящее время ведущем этапе развития нейропсихологии акцент исследователей сместился на взаимодействие больного с окружающим миром, с реальными условиями его жизнедеятельности. На этом этапе возникла культурноисторическая (социально-историческая) нейропсихология. Важным достижением культурно-исторического подхода в нейропсихологии являются разработка и внедрение культурно-специфических методов в нейропсихологическую диагностику.

Обсуждаются возможности интеграции качественного и количественного подхода в нейропсихологической диагностике. Подчеркиваются неоднозначность и различия понятий нейропсихологии и нейронауки и роль культурно-исторического подхода в современной нейропсихологической диагностике, реабилитации и коррекции.

Можно выделить три основные характеристики развития нейропсихологии после Лурия: 1) экстенсивное распространение нейропсихологической диагностики на новые нозологические группы больных и новые области исследований; 2) сочетание качественного и количественного подхода; 3) социально-личностная ориентация.

Луриевский подход, отличающийся многосторонностью и креативностью, продолжает стимулировать развитие нейропсихологии как в России, так и за рубежом.

Ключевые слова: нейропсихология; этапь развития нейропсихологии; синдромный анализ; А. Р. Лурия; культурно-историческая нейропсихология.

\section{The Growth of Neuropsychology (Historical Introduction)}

The second half of the XX century and beginning of XXI century have witnessed phenomenal growth of both theoretical and applied neuropsychology. Many evidences testify this growth:

1. Creation of specialty divisions in most National Psychological Associations.

2. Creation of National Neuropsychological Societies, such as, the Sociedad Latinoamericana de Neuropsicología (SLAN), the South African Clinical Neuropsychological Association (SACNA), Polish Neuropsychological Society, the Australasian Society for the Study of Brain Impairment (ASSBI) and more.

3. The International Neuropsychological Society (INS) was established in 1967 in the USA with only a few members (Rourke \& Murji, 2000), with its membership growing to about 5,000 by 2015 . Its first president was Karl H. Pribram. The Journal of the International Neuropsychological Society (its official journal), is currently published ten times per year. INS holds two meetings each year. Over the past five years, the Annual Meeting has averaged approximately 1700 attendees per year.

4. Federation of European Societies of Neuropsychology (FESN) was created in 2008 and unifies the neuropsychological societies of Austria, Belgium, Czech Republic, Denmark, Estonia, Finland, France, Germany, Greece, Italy, Luxemburg, Nether- 
lands, Norway, Poland, Portugal, Spain, Sweden Switzerland, Turkey, and United Kingdom with biennial scientific conferences.

5. International Society of Applied Neuropsychology (ISAN) was established in 2016 in Barcelona, to contribute to the progress in neuropsychological assessment and rehabilitation of children and adults with disturbances (underdevelopment) of cognitive functioning, personality and behavior as well as to increase in quality of training of specialists in applied neuropsychology.

This international growth is due to the abilities of contemporary professional neuropsychologists to meet different purposes beyond understanding of brain-behavior relationships (Luria, 1965, 1969; Korsakova \& Glozman, 1986; Glozman, 1999a, 2012; Homskaya, 2005):

1. Neuropsychological study of normal and abnormal mental functioning.

2. Focal diagnosis of the brain damage underlying observed defects of mental functioning.

3. Differential diagnosis between organic and socio-psychological etiologies of disturbances.

4. Comprehensive description of impairments of higher mental functions and the identification of the factors underlying such impairments.

5. Prediction and prevention of social manifestations and consequences of higher mental function disturbances, such as learning disabilities, school maladjustment and others.

6. Neuropsychological study of individual differences.

7. Evolution of individual treatment plans and strategies for remediation of cognitive disorders.

8. Evaluation of the outcome of different kinds of treatment: surgical, pharmacological, psychological, and others.

9. Determination of the best methods of treatment for different cases (both children and adults).

This list can be continued:

It is probable; however, that neurodiagnostic evaluation by neuropsychologists will prove to be less important than the ability to specify precisely behavioral deficits and strengths. Perhaps most important will be the neuropsychologist's ability to propose precise training programs for motor, sensory and cognitive deficits (Wedding, Horton, \& Webster, 1986, p. ix).

The revealed behavioral deficits orient the rehabilitation program while the revealed strengths determine the strategy of training. The final task is to meet "the challenge of alleviating human distress and promoting social well-being for the brain-impaired population" (Ibid., p. x).

Thus, we see both the variety of tasks successively solved by contemporary neuropsychology, as well as the dynamics in their relative importance. Let us describe now the actual state of theoretical and applied neuropsychology. 
The neuropsychology shows now both intensive and extensive development, as proven by the increased number of neuropsychological techniques and by the extended sphere of their application, not only in neurosurgery and neurology but also in psychiatry, gerontology, the somatic clinic, in normal and special education, etc. (Korsakova, 1998; Glozman, 1999b).

Neuropsychology can provide valuable understanding in the treatment of such chronic diseases as lupus, chronic obstructive lung diseases (emphysema), cardiovascular disorders, and certain types of oncological disorders...In this respect, any medical complication or treatment having a direct or indirect impact on neural integrity should be considered within the scope of neuropsychology (Horton \& Puente, 1986, p. 18).

Neuropsychological consequences appear after different diseases or deviated evolution. It makes neuropsychology the important part of the psychology of health (Ryan, Vega, Longstreet, \& Drash, 1984).

Let us speak further about neuropsychological techniques or tests. Their history passed a long way from description of revealed symptoms to their scoring and then from scoring to their analysis (see details in Glozman, 2012). Neuropsychological tests differ in specificity and sensitivity. Highly specific tests help to make a diagnosis, whereas highly sensitive tests can refute a diagnosis (Smith, Ivnik, \& Lucas, 2008).

The evolution of neuroimaging techniques (MRI, CT, PET), beginning in the late 1960s, does not decrease the diagnostic value of neuropsychological assessment in neurology and neurosurgery. "As exciting as these new diagnostic techniques are, they still fail (because of (the) inherent aspects of the technology) to provide an adequate presentation of human behavior" (Horton \& Puente, 1986, p. 18). Luria wrote:

I am inclined to strongly reject an approach in which these auxiliary aids become the central method and in which their role as servant to clinical thought is reversed so that clinical reasoning follows instrumental data as a slave follows its master (Cole, Levitin, \& Luria, 2006, p. 177).

An important diagnostic task is to reveal disorders of higher mental functions in cases where cerebral organic disturbances are not evident (for instance, after toxic injuries or vascular dysfunctions, or mental delay in children). Early neuropsychological diagnosis of mental dysfunctions (in preschool age or at the initial phases of disease) helps to prevent an aggravation of defects and to select the most efficient methods of surmounting defects. It was proven that a remediation of learning-disabled children is more effective when it is based on neuropsychological assessment data (Hartlage, 1975; Akhutina \& Pylayeva, 2008; Glozman, 2013).

Therefore, the neuropsychological assessment has differential diagnostic, remediative, preventive, and prognostic aspects. 
In order to achieve these purposes, according to Luria:

Neuropsychological assessment must not be limited to a simple statement that one or another form of mental activity is below level. The investigation must be always a qualitative (structural) analysis of the symptom under study, specifying the observed defect, its possible character, and the factors causing it (Luria, 1969, p. 306).

For example, it is well known that most patients with brain disturbance (both organic and functional) complain of memory troubles. "But, this 'memory trouble' can be provoked by different causes. It is natural that we should precise with special methods the structure and the meaning of this symptom to qualify it and the underlying factors" (Ibid., p. 303). A. R. Luria has named such an approach the syndrome analysis.

To understand the value of this approach one should look in the history of neuropsychology.

\section{The History of Neuropsychology}

It was stated, that neuropsychology has "a long past, but a short history" (Horton \& Puente, 1986, p. 3).

Neuropsychology started by descriptions by neurologists and psychiatrists of individual cases with mental function disturbances (predominantly speech and memory) with attempts to relate them to an injury of definite brain areas. Such first attempts date as far back as 3000-2550 BCE (Walsh, 1978). At the end of the 16th and the beginning of the 17th centuries, some observations on localization of mental functions appeared in the works of René Descartes, but a real explosion of such observations in all countries was due to autopsy legalization in the 19th century medicine: P. Broca, 1861; C. Wernicke, 1874; A. Ya. Kojevnikov, 1874; S. S. Korsakov, 1887; K. Goldstein, 1925; K. Lasley, 1929; M. B. Krol, 1934; A. R. Luria, 1947; R. Reitan, 1955; R. Sperry, 1961; M. Gazzaniga, 1970 (see details and references in Glozman, 2012). It was the period of big discussions in international neurological literature between followers of localizationism (brain is an aggregate of "Centers" each of which is related to a particular function) and of antilocalizationism (brain is equipotential, that is it realizes all mental function as a whole). The discussion stopped when Luria has created his theory of dynamic and systematic cerebral organization of mental processes. It means that each mental function is based on the integrative functioning of different brain regions united in brain functional systems. With this, "the structure of the organism presupposes not an accidental mosaic, but a complex organization of separate systems. This organization is expressed paramountly in a functional correlation of these systems... they unite as very definite parts into an integrated functional structure" (Luria, 1932, pp. 6-7).

This Luria's idea has been integrated into contemporary neuropsychology and cognitive neurosciences. Today it is considered as a basic idea, not as a specific author's pro- 
posal. Contemporary brain research has emphasized that brain systems or brain circuits realize cognitive processes. Therefore, a disturbance of the same higher mental function (like speech or memory) may be revealed when different brain areas are damaged. It necessitates a specific procedure of neuropsychological assessment.

Luria describes the neuropsychological assessment in the following way:

In experimental work a scholar usually begins by choosing a specific problem. Then he constructs a hypothesis and selects methods for testing his hypothesis. He arranges matters so that he can more easily focus his attention on those facts that will prove or disprove it. He is able to ignore all data that do not contribute to his analysis of the problem and to the proof of his hypothesis.

By contrast, in clinical work, the starting point is not a clearly defined problem but an unknown bundle of problems and resources: the patient. The clinical investigator begins by making careful observations of the patient in an effort to discover the crucial facts. In the beginning he can ignore nothing. Even data that on the first glance seem insignificant may turn out to be essential. At some point the vague contours of factors that seem important begin to emerge, and the clinician forms a tentative hypothesis about the problem. But it is still too early for him to say definitively whether the facts he has picked out are important to the problem or extraneous. Only when he has found a sufficient number of compatible symptoms that together form a "syndrome" he has a right to believe that his hypothesis about the patient might be proved or rejected (Luria, 1979/1982, p. 132, bolded by J. Glozman).

So, Lurian neuropsychological assessment is an individualized assessment of disturbances, that presupposes a qualitative estimation of symptoms, i. e. detecting a primary deficit, its systemic consequences and compensatory reorganization.

The Lurian syndrome analysis not only permits an understanding of why the subject was poor at or unable to perform a given task, but it also allows us to see what other tasks, with similar cognitive demands (structure), could present difficulties for this individual. Even more important is ability of Lurian approach to predict the types of tasks accessible for the patient and the types of cueing efficient for him/her in conditions of dialogue interaction with the patient during neuropsychological assessment. In other words, Lurian approach is oriented on the process of test fulfilment (the means by which the performer achieves or better the result or the level of necessary help or stimulation), more than on the test result - the level of performance on a task (accuracy, time, number of mistakes and so on) with reference to some expected (normative) level of performance.

Thus, qualitative analysis, or psychological qualification of the deficit, includes two main points. First, determining what is characteristic and specific for a particular symptom and what differentiates it from other known symptoms capable of disturbing the same mental function. Second, pinpointing the common "factor" that associates symptoms of different mental function disturbances arisen as a result of brain damage (Mikadze, Ardila, \& Akhutina, 2019, p. 796). 
It permits both: a better understanding of patient's problems and the selection of appropriate methods of his/her rehabilitation.

The figure 1 illustrates the specific features of Lurian assessment.

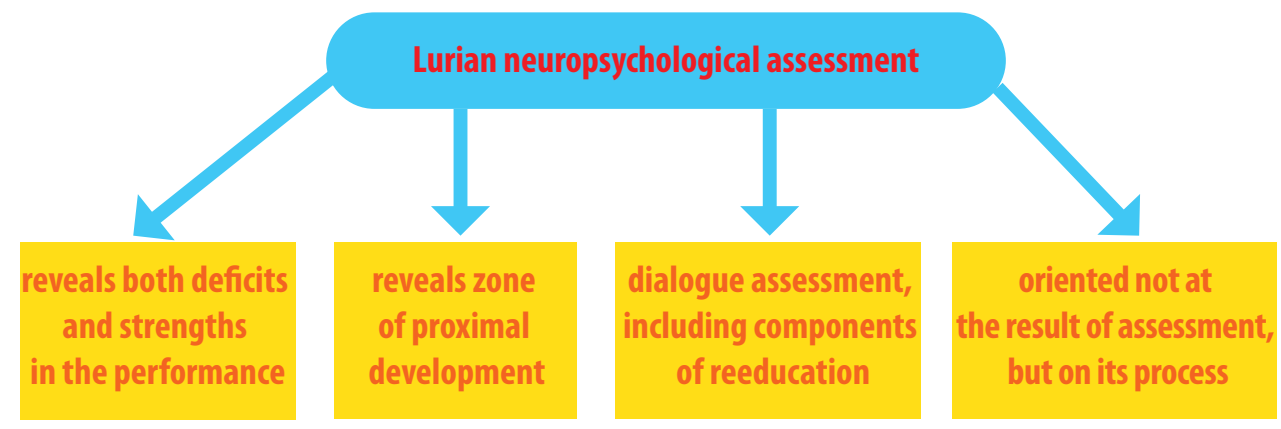

Figure 1. Specific features of Lurian assessment

\section{Definitions of Neuropsychology and its Evolution}

The field of the word neuropsychology includes as synonyms cognitive neuropsychology, clinical neuropsychology, behavioral neurology and behavioral neuropsychology, experimental neuropsychology, neurosciences, physiological psychology and more. From the other side, neuropsychology enters in the semantic field of neurosciences together with neuroimaging, neurophysiology, cognitive neurosciences, neuroanatomy, neurobiology, neurogenetics, neurochemistry and even neuro-economics. Therefore, different authors have advanced multiple definitions of neuropsychology. The most popular is the definition by M. Meier (1974): "Neuropsychology is the scientific study of brain-behavior relationship" (cited by Horton and Puente, 1986, p. 5). According to Horton and Puente (1986) this definition addresses the most fields of neuropsychology, but it fails to address the new field of behavioral neurology and neuropsychology, which utilizes a qualitative approach to the conceptualization of neurobehavioral phenomena. The difference between behavioral neurology and behavioral neuropsychology, according to Horton (1979) is in the treatment philosophy of the last, that is the major emphasis upon the problems of rehabilitation, reinforcement. Very close to Luria's approach are the ideas that "inclusion of data from neuropsychological assessment strategies would be helpful in the formulation of hypotheses regarding antecedent conditions (external or internal) for observed phenomena of psychopathology" (Horton, 1979, p. 20). With this the "inherent variables, such as thoughts and images should be seen as legitimate concepts in the functional analysis of human behavior" (Horton \& Puente, 1986, p. 7).

The definition by Meier is very close to that done by A. R. Luria (1973), but being a founder of applied fields of neuropsychology, he added to this definition "a study of possibilities to use this knowledge for early and precise neuropsychological assessment and scientifically based rehabilitation of functions" (Luria, 1973, p. 10). It approaches Luria's 
definition to that of behavioral neuropsychology. Change in terms and concepts "is a fact of life that is more salient with each passing day" (Horton \& Puente, 1986, p. 19).

The evolution of neuropsychology conceptualizing and definition coincides with the universal tendency to replace a static neuropsychology, relating the individual's behavior to fixed cerebral lesions, by a dynamic neuropsychology, which analyzes the dynamics of brain-behavior interaction (Tupper \& Cicerone, 1990; Glozman, 1999a, 2007). The following model represents this evolution in neuropsychology through three overlapping and coexisting phases, different in the main emphasis for neuropsychologists (see Figure 2).

I II III
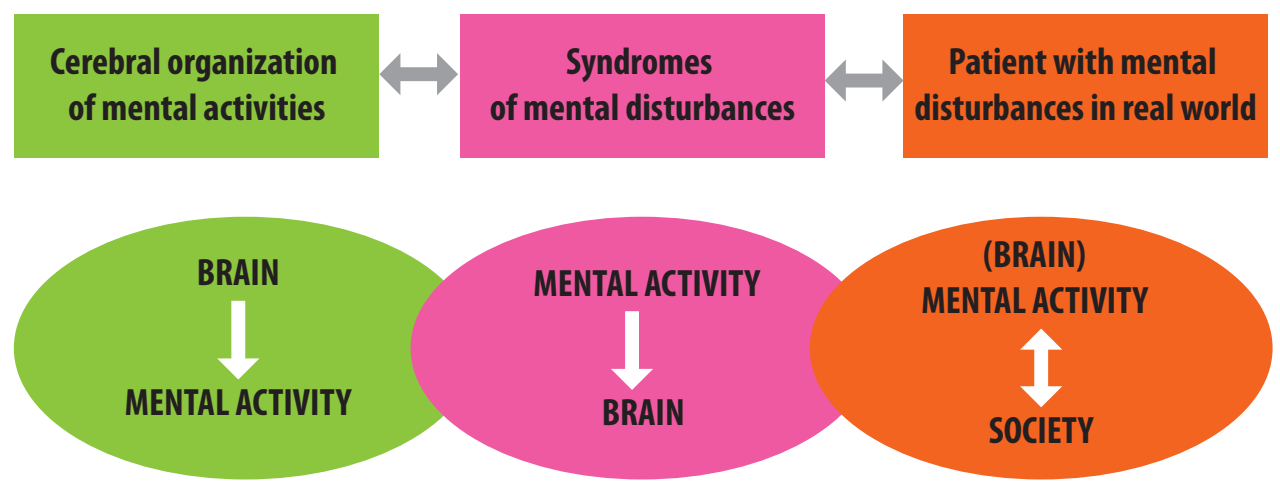

Figure 2. Model of evolution in neuropsychology

In the first phase, the emphasis for neuropsychologists was on the brain and its relationship to different behaviors. The above definition of neuropsychology (brain-behavior relationships) is relevant to this first phase in neuropsychology evolution.

The neuropsychology of this period was considered by Luria, as well as by occidental neuropsychologists, to be a "field of practical medicine" (Luria, 1973, p. 17). The main and most valuable attainment of this phase is a revision by Luria of concepts of localizationism and antilocalizationism and the creation of the theory of the dynamic and systematic cerebral organization of mental processes. This progress resulted in the functional analysis of different brain systems and description of frontal, parietal, temporal, and other syndromes. The recent evolution of this approach follows three main lines:

1. Study of functions of the right hemisphere and interhemispheric interactions for different types of memory, perception, and reasoning.

2. Research in subcortical brain pathology.

3. Studies of cerebral mechanisms of mental, neurotic and somatic diseases.

In the second phase of neuropsychology evolution, the structure of each mental activity has been the focus of attention and afterwards its localization in the brain. "Although Lurias interpretation of human cognition was proposed several decades ago... new scientific and technological advances have in large measure supported many of his ideas and hypotheses". (Kotik-Friedgut \& Ardila, 2019, p. 2). The second phase gave birth to different syndromes of mental disturbances: local, resulting in neuropsychology of memory (Luria, 1976a), 
neurolinguistics (Luria, 1976b); diffuse syndromes after cerebral vascular pathology (Moskovich, 2004), syndromes of underdevelopment or not typical development, resulting in learning disabilities (Glozman, 2013); and also cognitive dysfunctions in normal subjects in specific functional states or with some individual particularities or accentuations in cognitive performances. This last line gave birth to neuropsychology of individual differences, which is an application of neuropsychological concepts and methods to the assessment of healthy subjects (Homskaya, Efimova, Budyka, \& Enikolopova, 1997).

The third and actually dominant phase of evolution in neuropsychology focuses on the interrelationship between a patient and his or her environment and integrates neuropsychological and real life data. It gave birth to new branches of neuropsychology: ecological neuropsychology: behavioral neuropsychology, neuropsychology of everyday life, neuropsychology of personality and communication, neuropsychology of family.

Many standardized neuropsychological measures have been criticized for poor ecological validity, that is they don't reflect patient's abilities in daily activity.

Ecological methods were created to allow for assessment of the mental and emotional state of the subjects using tests and questionnaires which provide quantitative estimation of frequent behaviors (functional status), and predicts possible daily life problems of a patient. Results are presented in the form of data pointing to the disturbance of certain behaviors instrumental for adaptation to social situation, daily life, and independent functioning (Mikadze et al., 2019, p. 797).

The emphasis of the assessments is now a shift from diagnostic evaluation to prognostic and corrective suggestions. The neuropsychological assessment should emphasize the subject's strengths, which are important in his/her correction (rehabilitation) program and predict his/her ultimate adaptation and integration into society.

Such an understanding is based on the Lurian patient centered approaches in neuropsychological assessment and rehabilitation, that is, the primary focus on the experience of individuals, their subjective interpretation and personal knowledge of health and disease, their coping strategies, self-esteem, emotional well-being and social interaction. The person-centered approach have long been considered as lacking scientific rigor, but it is becoming now more and more recognized. It permits to explain, why people who apparently are exposed to the same damages, who even cope in similar ways and have equivalent social support have different degree of strain and depression and different outcome after rehabilitation. From the person-centered view Quality of Life means the perception and evaluation by the patient (her or himself) of the impact that the disease and its consequences have produced in her/his life. The optimal Quality of Life is the patient's self-satisfaction with the mental and physical features of own life and the results of the rehabilitation program.

These ideas predominant at the third phase of neuropsychology evolution prepared its transformation in social-historical or cultural-historical neuropsychology. Both terms are used as synonyms in the literature. 


\section{Social-Historical Neuropsychology}

Vygotsky and Luria developed the idea that cognitive processes descend from complex interaction and interdependence between biological factors (the individual mind), which is part of physical nature, and cultural factors, which appear in the evolution of a human being. This social-historical approach in neuropsychology looks for the origins of human conscience and mental activity not inside the brain, nor in the mechanisms of nervous processes, but in the context of human social life.

We need to step outside the organism to discover the sources of specifically human forms of psychological activity and the way natural processes such as physical maturation and sensory mechanisms become intertwined with culturally determined processes to produce the psychological functions of adults (Luria, 1979/1982, p. 43).

The experimental proves of these ideas about culture, especially schooling as a determinant of cognitive processes were received in famous expeditions of Luria to Uzbekistan during 1931 and 1932, which were planned and analyzed in cooperation with Lev Vygotsky.

Scribner and Cole (1978), Gilbert (1986) partially replicated Luria's field studies in South Africa with near-identical results. Later on, Tulviste (1991), Glozman (2018) also found similar results.

The role of Luria in the development of social-historical psychology was underlined by Vasily Davydov, former Director of Moscow Psychological Institute:

An analysis of theoretical and methodological works by Luria (particularly his last works) proves, that he could not imagine another psychology than social-historical looking for origins of human conscience not inside the brain, not in the mechanisms of nervous processes but in the human social life - the real base for conscious activity (Davydov, 1998, p. 14-15).

The same was said by Jerome Bruner: "For Luria the brain was an instrument for making culture accessible to mind. ... for him the 'internalization of culture' was a mastering of possible worlds" (Bruner, 2005, p. XII).

One of the important consequences of cultural-historical approach in neuropsychology was the introduction of cultural adjustments in neuropsychological diagnostic tests, both verbal and nonverbal (Nell, 2000; Agranovich, 2004; Nielsen et al., 2018). All norms for neuropsychological tests should be culture specific to provide their reliability. Standard procedure of test administration does not provide its relevance to culture standards. A test translation to another language needs a selection of a new material corresponding to linguistic and cultural features. Cultural specificity of neuropsychological assessment is both social and ethical problem. Cultural equality of tests is as important as their statistical validity for assessment of mental functioning. 
Another application of cultural-historical approach in neuropsychology are researches of social brain. The term social brain was introduced in neuropsychology by M. Gazzaniga (1985) in his studies of emotional and social communication disturbances after right hemisphere damages. Later this term was used to show how human brain processes the social information and determines the mind as a whole (Brüne, Ribbert, \& Schiefenhovel, 2003; Insel \& Fernald, 2004; Dunbar, Gamble, \& Gowlett, 2010).

The relation between social cognition and social behavior are still largely unknown, or very complex and involved in connections with other regulatory processes. It is highly probable, that there is no simple translation of social cognition into social behavior. Nevertheless, pathology of those two components leads to interpersonal maladjustment of patients with brain injury. "Cultural-historical approach in neuropsychology means a change in social brain study orientation from localization to problems of social and cultural regulation of cerebral functions" (Glozman \& Krukov, 2013, p. 77).

The cultural-historical approach in neuropsychology influenced also the neuroscience up to appearance of a new field of research - cultural neuroscience concerned with studying the influences of culture on brain anatomy and function (Chiao \& Blizinsky, 2016). A. Toomela (1996) even postulated that culture transforms brain. It can be explained by the law of double interaction between the brain maturation and the formation of the mental functions determined by P. Ya. Halperin (a friend and colleague of Luria): on the one hand, for the emergence of a function a certain degree of maturity of the nervous system is required, on the other, the very functioning and the active and developing remedial effect influence the maturation of structural elements of the brain (Halperin, Zaporozhets, \& Karpova, 1978). Lurian theory of higher mental functions formation well explains this law of morphological and functional interaction: "They [mental functions, J.G.] were all formed in the course of long historical development; they are social in their origin" (Luria, 1973, p. 29). Luria shared Vygotsky's "principle of extracortical organization of complex mental functions... implying... that all types of human conscious activity are always formed with the support of external auxiliary aids" (Luria, 1973, p. 31). The environment and surrounding people determine child cognitive development. Vice versa, child abuse has negative effect on his/her brain development (Perry, 2002).

However, different mediators and means, or significantly different details within them (e. g., the direction of writing and the degree of letter sound correspondence, orientation by maps, digital internet navigator, or by the behavior of sea-birds) may be developed, and in fact are developed in different cultures. Therefore, the analysis of higher mental functions must necessarily take into account these cross-cultural differences (Kotik-Friedgut \& Ardila, 2019, p. 2).

Consequently, to foresee how the technological advances can impact the development of the higher mental functions, therefore the neuropsychology of 21st century must incorporate the environmental changes (Ardila, 2013).

It is especially evident in works dealing with theory and practice of neuropsychological rehabilitation. 


\section{Neuropsychological Rehabilitation}

During the 21st century, neuropsychological rehabilitation has become one of the major areas in neuropsychology professional activity [e.g., Evans, Gast, Perdices, and Manolov (2014); Sohlberg and Mateer (2017)].

In "Traumatic aphasia" (Luria, 1947/1970) and "Restoration of functions after brain injury" (Luria, 1948/1963) Luria described two main strategies of higher mental functions rehabilitation: disinhibition of inhibited functional components, and reorganization of the affected functional systems, using inter- and intra-system functional restructuring.

Vygotsky wrote:

Initially all these functions (higher forms of speech, cognition, and action) operate in intimate connections with external activity and only later on change into the inner activity. Research into compensatory functions which develop in these disorders also shows that objectification of a disturbed function, i. e. bringing it outside and changing it into external activity, is one of the basic roads in the compensation of disorders (Vygotsky, 1997, p. 143).

This principle was first realized in aphasiology as the so-called socio-psychological aspect of rehabilitation, studying social relationship between patient and other members of the therapeutic group (Tsvetkova, Glozman, Kalita, Maximenko, \& Tsyganok, 1979), as well as changes derived from relationship between therapist and patient (Quintino-Aires, 2005), then in studies of interrelations between communication disorders and personality in different nosological groups (Glozman, 2004) and in developmental neuropsychology (Glozman, 2013).

The optimal organization of communication within the therapy group provides the conditions for the mobilization of creative activity in the patient's mental sphere, personality and aids the growth of one's self-perception and "mental growth"... The internal (the subject) acts trough the external and in doing so, changes itself (Glozman, 2004, pp. 148-149).

Through internalization (Vygotsky, 1997), interpsychological (social/relational) forms are transferred to the intrapsychological (personal) forms of meaning.

The cultural-historical approach in neuropsychological rehabilitation of brain damaged patients and in remediation of learning disable children consists in further development of the theory of mediation. During the late 1920's - early 1930th Luria and Vygotsky tried to rehabilitate Parkinsonian patients in the laboratory of neuropsychology at neurological hospital of Moscow University. The young researchers have created a program compensating motor subcortical disturbances in Parkinson's disease through a cortical (visual) mediation of movements (Luria, 1948/1963; Vygotsky, 1978). The program consisted of two main stages:

1. Training stage, when the patient was trained to use cues with a gradual decrease in external cueing. 
2. Interiorization stage, when the external cues are gradually replaced by their internal images, that become internal means for the patient to control own motor behavior.

We used this idea of mediation as a means of transformation of functional systems in an integrated program for rehabilitation of different mental functions: memory, attention, writing, vocabulary, counting, problem solving, space orientation, movements and emotional sphere both in parkinsonian patients and in learning disable children (Glozman, 1999b, 2013).

The rehabilitation effect depends from teaching modalities: participative-guided and peer-collaborative approaches are more efficient than classical-expositive methods. Important are the optimal individualized choice of mediating means and the interhemispheric interaction: interfunctional mediation (semantic/visual) is in most subjects more efficient, than intrafunctional with some limitation for patients with specific features of interhemispheric interaction.

In general, the rehabilitation process for all subjects must be oriented to the personal goals of the patient and his/her family.

\section{Integration of Qualitative and Quantitative Approaches}

As already stated, Luria's approach presupposes a qualitative analysis of the symptom under study, based upon an understanding of the factors, underlying complex psychological activities. The quantitative evaluation of disturbances is of primary value for determining the dynamics of change in cognitive functioning during neuropsychological follow-up, and for measuring the outcome of rehabilitative or remedial procedures.

We proposed a generalized system of rating of Luria's assessment method a double system of patient's performances evaluation: the first step is to make a list of possible defects in each task fulfillment (qualitative evaluation). The examiner puts plus or minus for each item in the list for every one patient. It results in:

1. Neuropsychological pattern of cognitive disorders for the examined patient.

2. Typical neuropsychological pattern of cognitive disorders for the studied group of patients.

3. Dynamics of the patterns after treatment: a disappearance of some symptoms (positive dynamics) or an appearance of the new ones (negative dynamics).

The second step consists in quantitative evaluation of the degree of each symptom and the severity of disturbances (a quantitative expression of the pattern of disturbances and of the level of the patient's performance) through a six points scoring system. This method takes account of normative reference, of the qualification of the symptoms (primary or secondary defects), conditions of mistake's corrections and possibilities to organize the test successful fulfillment with or without external assistance (Glozman, 1999a, 2012). 


\section{Conclusions}

Luria's approach or Lurianism [the term, proposed by J. Peña-Casanova (1989)] is based on systemic cultural-historical approach. Due to it, Luria has created a meta-theory of human mental functions.

Luria's neuropsychology is an interdisciplinary field that investigates interrelations among culture, mind and the brain. This assured the uniqueness of Lurian neuropsychology (Moskovich, Bougakov, DeFina, \& Goldberg, 2002).

Luria's neuropsychology is a model of how to combine science and humanism, theory and practice, how to see the observed phenomena as a complex. Scientific observation is not just phenomenological description of separate facts.

Its main goal is to view an event from as many perspectives as possible. The eye of science does not probe "a thing" or an event isolated from other things or events. Its real objective is to see and understand the way a thing or event relates to other things or events (Cole et al., 2006, p. 177).

To inherit all these features of Lurianism in their complexity, integration and inter-influence means to inherit in full the legacy of Alexander Luria.

Three main trends can be seen in the evolution of neuropsychology after Luria:

1. Extensive further expansion of research and practice, that is, embracing numerous new domains and nosological patient groups.

2. Integration of qualitative and quantitative approaches for analysis of neuropsychological assessment results.

3. A social, cultural and personality-based orientation in most neuropsychological studies all over the world.

It should be underlined, that these trends meet well the main principles of a psychological study, formulated by Luria in his first book, as far as in 1922 (Luria, 1922/2003):

- To deal with the concrete personality, the living human being, as a biological, social and psychological unity.

- To study individual regularities, uniquely determined sequences, that is to combine a description of individual, unique processes with the study of lawful, regular processes.

- To study an individual human mind as a whole and the particular mental phenomena as functions, elements of this whole, developing in this concrete human personality, with the possibility of change through the transformation of social conditions.

- To study individual values of the examined psychological phenomena for the life of the actual personality.

All the previously mentioned shows, that Luria's creative and comprehensive approach stimulates the further evolution of neuropsychology in Russia and throughout the world.

\section{Acknowledgements}

This study has been supported by the Russian Foundation for Basic Research, project \#18-013-00721). 


\section{References}

Agranovich, A. (2004). Cross-cultural differences in neuropsychological performance: A comparison between Russian and American samples. In T. V. Akhutina, J. M. Glozman, L. I. Moskovich \& D. Robbins (Eds.), A. R. Luria and contemporary psychology: Festschrift celebrating the centennial of his birth (pp. 181-188). New York: Nova Science.

Akhutina, T. V., \& Pylayeva, N. M. (2008). Surmounting learning disabilities. Neuropsychological approach. Moscow: Peter. [In Russian]

Ardila, A. (2013). A new neuropsychology for the XXI century. Archives of Clinical Neuropsychology, 28(8), 751-762.

Brüne, M., Ribbert, H., \& Schiefenhovel, W. (2003). Social brain: evolution and pathology. New York: Wiley.

Bruner, J. (2005). Preface. In T. V. Akhutina, J. M. Glozman, L. I. Moskovich \& D. Robbins (Eds.), A. R. Luria and contemporary psychology: Festschrift celebrating the centennial of his birth (p. XII). New York: Nova Publishers.

Chiao, J. Y., \& Blizinsky, K. D. (2016). Cultural neuroscience. Social neuroscience: Biological approaches to social psychology. New York: Routledge, Taylor \& Francis.

Cole, M., Levitin, K., \& Luria, A. (2006). The autobiography of Alexander Luria. A dialogue with the making of mind. Mahwah, NJ: Lawrence Earlbaum.

Davydov, V. V. (1998). On specific orientations in Luria's studies. In E. D. Homskaya \& T. V. Akhutina (Eds.), First international Luria memorial conference proceedings (pp. 14-20). Moscow: Russian psychological association press. [In Russian]

Dunbar, R., Gamble, C., \& Gowlett, J. (2010). Social brain, distributed mind. Oxford: Oxford University Press.

Evans, J. J., Gast, D. L., Perdices, M., \& Manolov, R. (2014). Single case experimental designs: Introduction to a special issue of neuropsychological rehabilitation. Neuropsychological Rehabilitation, 24, 305-314.

Gazzaniga, M. (1985). The social brain: Discovering the networks of the mind. New York: Basic Books.

Gilbert, A. J. (1986). Psychology and social change in the third world: A cognitive perspective. Unpublished Doctoral Dissertation, University of South Africa, Pretoria, South Africa.

Glozman, J. M. (1999a) Qualitative and quantitative integration of Lurian procedures. Neuropsychology Review, 9 (1), 23-32.

Glozman, J. M. (1999b). Russian neuropsychology after Luria. Neuropsychology Review, 1, 33-44.

Glozman, J. M. (2004). Communication disorders and personality. New York: Kluwer Academic.

Glozman, J.M. (2007). A. R. Luria and the history of Russian neuropsychology. Journal of the History of the Neurosciences, 16, 168-180.

Glozman, J. M. (2012). Neuropsychological assessment: Qualitative and quantitative evaluation of data. Moscow: Smysl Publishing House. [In Russian]

Glozman, J. M. (2013). Developmental neuropsychology. London ; New York: Psychology Press / Taylor and Francis Group.

Glozman, J. M. (2018). A reproduction of Luria’s expedition to Central Asia. Psychology in Russia: State of the Art, 11, 2, 7-16. https://doi.org/10.11621/pir.2018.0200

Glozman, J. M., \& Krukov, P. (2013). The social brain. Psychology in Russia: State of the Art, 6, 3, 68-78. 
Halperin, P. Ya., Zaporozhets, A. V., \& Karpova, S. N. (1978). Actual problems of developmental psychology. Moscow: Moscow Univ. Press. [In Russian]

Hartlage, L. C. (1975). Neuropsychological approaches to predicting outcome of remedial education strategies for learning disabled children. Pediatric Psychology, 3, 23-28.

Homskaya, E. D. (2005). Neuropsychology (Fourth ed.). Saint Petersburg: Peter. [In Russian]

Homskaya, E. D., Efimova, I. V., Budyka, E. V., \& Enikolopova, E. V. (1997). Neuropsychology of individual differences. Moscow: Russian Pedagogical Agency Press. [In Russian]

Horton, A. M. (1979). Behavioral neuropsychology: rationale and presence. Clinical Neuropsychology, 1, 20-23.

Horton, A. M., \& Puente, A. (1986). Human Neuropsychology: an Overview. In D. Wedding, M. A. Horton \& J. Webster (Eds.), The Neuropsychology Handbook. Behavioral and clinical perspectives (pp. 3-22). New York: Springer Publishing Company.

Insel, Th. R., \& Fernald, R. D. (2004). How the brain processes social information: Searching for the social brain. Annual Review of Neuroscience, 27, 1, 697-722.

Korsakova, N. K. (1998). Neuropsychogerontology: Development of A. R. Luria's school of ideas. In E. D. Homskaya \& T. V. Akhutina (Eds.), First international Luria memorial conference proceedings (pp. 249-254). Moscow: Russian Psychological Association Press. [In Russian]

Korsakova, N. K., \& Glozman, J.M. (1986). Neuropsychological help in neurosurgery and neurology. Psychological Journal, 3, 71-77. [In Russian]

Kotik-Friedgut, B., \& Ardila, A. (2019). A. R. Luria's cultural neuropsychology in the 21st century. Culture \& Psychology, 26, 2. Retrieved from https://journals.sagepub.com/doi/ abs/10.1177/1354067X19861053

Luria, A. R. (1922/2003): The principles of real psychology. In J. M. Glozman, D. A. Leontiev \& A. G. Radkobskaya (Eds.), A.R. Luria. Psychological tribute (pp. 295-384). Moscow: Smysl. [In Russian]

Luria, A. R. (1932). The Nature of human conflicts. New York: Liveright.

Luria, A. R. (1947/1970). Traumatic aphasia: Its syndromes. The Hague: Mouton.

Luria, A. R. (1948/1963). Restoration of function after brain injury. New York: Macmillan.

Luria, A. R. (1965). Neuropsychological analysis of focal brain lesions. In B. B. Wolman (Ed.), Handbook of clinical psychology (pp. 689-754). New York: McGraw-Hill.

Luria, A. R. (1969). Higher cortical functions in man (2 $2^{\text {nd }}$ ed.). Moscow: Moscow University Press. [In Russian] (English translation: New York: Basic Books, 1980).

Luria, A. R. (1973). The working brain. New York: Basic Books. [2 ${ }^{\text {nd }}$ ed. Moscow: Akademia, 2002]

Luria, A. R. (1976a). The neuropsychology of memory. Washington: Winston.

Luria, A. R. (1976b). Basic problems of neurolinguistics. The Hague: Mouton.

Luria, A.R. (1979/1982). The making of mind. Moscow: Moscow University Press. [English edition: Cambridge, MA: Harvard University Press, 1979]

Meier, M. J. (1974). Some challenges for clinical neuropsychology. In R. Reitan \& L. Davison (Eds.), Clinical neuropsychology. Current status and application (pp. 289-323). New York: Wiley.

Mikadze, Yu. V., Ardila, A., \& Akhutina, T. V. (2019). A. R. Luria’s approach to neuropsychological aassessment and rehabilitation. Archives of Clinical Neuropsychology, 34, 795-802.

Moskovich, L. I. (2004). Cerebral hemisphere asymmetry on the cortical and subcortical levels. In T. V. Ahutina, J. M. Glozman, L. I. Moskovich, \& D. Robbins (Eds.), A. R. Luria and Contempo- 
rary Psychology: Festschrift celebrating the centennial of the birth of Luria (pp. 11-13). New York: Nova Science.

Moskovich, L., Bougakov, D., DeFina, Ph., \& Goldberg, E. (2002). Pathway to prominence. A. R. Luria: Pursuing neuropsychology in a swiftly changing society. New York: Psychology Press.

Nell, V. (2000). Cross-cultural neuropsychological assessment: Theory and practice. Mahwah, NJ: Lawrence Erlbaum Associates.

Nielsen, T. R., Segers, K., Vanderaspoilden, V., Bekkhus-Wetterberg, P., Minthon, L., Pissiota, A., \& Waldemar, G. (2018). Performance of middle aged and elderly European minority and majority populations on a cross cultural neuropsychological test battery (CNTB). Clinical Neuropsychology, 24, 1-20.

Peña-Casanova, J. (1989). A. R. Luria today: Some notes on "Lurianism" and the fundamental bibliography of A. R. Luria. Journal of Neurolinguistics, 4(1), 161-178.

Perry, B. D. (2002). What childhood neglect tells us about nature and nurture. Brain and Mind, 3, 79-100. Quintino-Aires, J. (2005). Socio-historical approach in psychotherapy with adults. In V.F. Spiridonov \& Yu. E. Kravchenko (Eds.), Cultural-historical approach and sociolization study. Proceeding of the Fifth conference in memory of Vygotsky (pp. 193-200). Moscow: Russian Humanity University Press.

Rourke, B. P., \& Murji, S. (2000). A history of the International neuropsychological society: The early years (1965-1985). Journal of the International Neuropsychological Society, 6 (4), 491-509. https:// doi.org/10.1017/s1355617700644077

Ryan, C., Vega, A., Longstreet, C., \& Drash, A. (1984). Neuropsychological changes in adolescents with insulin-dependent diabetes. Journal of Clinical Psychology, 3, 335-342.

Scribner, S., \& Cole, M. (1978). Literacy without schooling: Testing for intellectual effects. Harvard Educational Review, 48(4), 448-461.

Smith, G., Ivnik, R., \& Lucas, J. (2008). Assessment techniques: Tests, test batteries, norms and methodological approaches. In J. Morgan \& J. Ricker (Eds.), Textbook of clinical neuropsychology (pp. 3857). New York: Taylor \& Francis. [2 ${ }^{\text {nd }}$ ed.: London: Routledge, 2018]

Sohlberg, M. M., \& Mateer, C. A. (2017). Cognitive rehabilitation: An integrative neuropsychological approach. New York: Guilford Publications.

Toomela, A. (1996). How culture transforms mind: A process of internalization. Culture \& Psychology, 2, 285-305.

Tsvetkova, L. S., Glozman, J. M., Kalita, N. G., Maximenko, M. Yu., \& Tsyganok, A. A. (1979). Socio-psychological aspect of aphasics rehabilitation. Moscow: Moscow University Press. [In Russian]

Tulviste, P. (1991). Horizons in psychology. The cultural-historical development of verbal thinking (M. J. Hall, Trans.). Hauppauge, New York: Nova Science Publishers.

Tupper, D. E., \& Cicerone, K. D. (1990). Introduction to the neuropsychology of everyday life. In D. Tupper \& K. Cicerone (Eds.), The neuropsychology of everyday life: Assessment and basic competences (pp. 3-18). Boston: Kluwer Academic Publishers.

Vygotsky, L.S. (1978). Mind in society. The development of higher psychological processes. Cambridge: Harvard University Press.

Vygotsky, L.S. (1997). The collected works of L.S. Vygotsky. Vol. 3. Problems of the theory and history of psychology [R. W. Rieber \& J. Wollock, Eds.]. London, UK: Plenum Press.

Walsh, K. W. (1978). Neuropsychology: A clinical approach. New York: Churchill Livingston. 
Wedding, D., Horton, M. A., \& Webster, J. (1986). Preface. In D. Wedding, M. A. Horton \& J. Webster (Eds.), The Neuropsychology Handbook. Behavioral and clinical perspectives (pp. IX-X). New York: Springer Publishing Company.

Original manuscript received February 2, 2020 Revised manuscript accepted March 19, 2020

To cite this article: Glozman, J.M. (2020). Neuropsychology in the past, now and in the future. Lurian Journal, 1 (1), 29-47. DOI:10.15826/Lurian.2020.1.1.5 